\title{
Fluordun konposatuak gure kostaldeko bizidunetan
}

\author{
(The presence of fluorinated compounds \\ in our coast organisms)
}

Itsaso Zabaleta*, Dennis Bilbao, Ekhine Bizkarguenaga, Ailette Prieto,
Olatz Zuloaga

Kimika Analitikoa Saila, Zientzia eta Teknologia Fakultatea (UPV/EHU)

*itsaso.zabaleta@ehu.eus

DOI: $10.1387 /$ ekaia.17830

Laburpena: Egun, konposatu per- eta polifluoratuek (PFAS) gure eguneroko bizitzan dituzten erabilera anitzak direla-eta, ingurunean gero eta nabariagoa da euren presentzia. Ur-ekosistemen egoera aztertzea helburu, organismo itsastarrak kutsaduraren adierazle ezin hobeak dira. Ildo horretan, lan honetan Frantziako, Euskal Herriko, Espainiako eta Portugaleko kostaldeetako lazunen (Chelon labrosus) gibelak eta ostrak (Ostrea edulis) aztertu dira. Gibelen kasuan, azido perfluorooktanosulfonikoa (PFOS), azido perfluorodekanoikoa (PFDA) eta perfluorooktanosulfonamida (PFOSA) izan dira laginak biltzeko puntu guztietan detektatutako PFAS-ak. Aipatzekoa da Urdaibaiko Erreserba Naturalean kokatuta dagoen Gernikako itsasadarrean aurkitutako PFOS-aren kontzentrazioak (443-1.214 ng/g), araztegiaren edota industriaren eragina nabarmenduz. Ostren kasuan, PFOS-a eta PFOSA izan dira detektatutako kutsatzaileak, betiere gibelean lortutako kontzentrazioak baino baxuagoak.

Hitz gakoak: Fluordun konposatuak, arrainen gibelak, ostrak.

Abstract: Nowadays, due to the wide range of applications, the presence of per- and polyfluoroalkyl substances is increasing in the environment. Aquatic organisms are very useful bioindicators in order to assess the health of the aquatic environment. Within this objective, grey mullet (Chelon Labrosus) livers and oysters (Ostrea edulis) of the French, Basque, Spanish and Portuguese coasts were analysed. In the case of the liver, perfluorooctane sulfonic acid (PFOS), perfluorodecanoic acid (PFDA) and perfluorooctane sulfonamide (PFOSA) were the detected target analytes in all the sampling points. Surprisingly high concentrations of PFOS (443-1,214 ng/g) were detected in the river of Gernika, which is placed in the Natural Reserve of Urdaibai, highlight- 
Itsaso Zabaleta, Dennis Bilbao, Ekhine Bizkarguenaga, Ailette Prieto, Olatz Zuloaga

ing the effect of the wastewater treatment plant (WWTP) and/or the industry. In the case of oysters, PFOS and PFOSA were detected at levels lower than those found in liver.

Keywords: Fluorinated compounds, fish liver, oyster.

\section{SARRERA}

Iaz albiste kezkagarria argitaratu zuen Greenpeacek zenbait etxe komertzial ezagunetako mendirako arropa eta osagarrietan konposatu perfluoratu (perfluorinated compounds, PFC, delako) toxikoak daudela esan zuenean [1]. Izan ere, konposatu per- eta polifluoratuak (per- and polyfluoroalkyl substances, PFAS, delakoak, ikus zenbait adibide 1. irudian) gure eguneroko bizitzan erabiltzen diren material eta tresna ugaritan aurki ditzakegu euren egiturak ematen dizkien propietate bereziei esker [2]. Alde batetik, fluor atomoz guztiz (per-) edo partzialki (poli-) ordezkaturiko kate hidrofobikoa dute, zeinak ura aldaratzeko propietatea ematen dien. Bestalde, kate hidrofobiko horri lotuta buru hidrofilikoa dute, modu neutroan, positiboan edo negatiboan kargatuta egon daitekeena. Buru hidrofiliko horrek koipea aldaratzeko gaitasuna ematen die. Egitura berezi horrek konposatu tentsio aktiboak bihurtzen ditu eta egun izan ditzaketen erabileren artean, aipatzekoa da babesgarri bezala duten erabilera anitza; hala nola, alfonbretan, kirol-arropetan, jakiak ontziratzeko materialetan eta sukaldeko tresnetan aurki daitezke. Era berean, konposatu kimiko bezala ere erabiltzen dira sua itzaltzeko aparretan, xanpuetan, tintetan eta margoetan, besteak beste $[3,4]$.
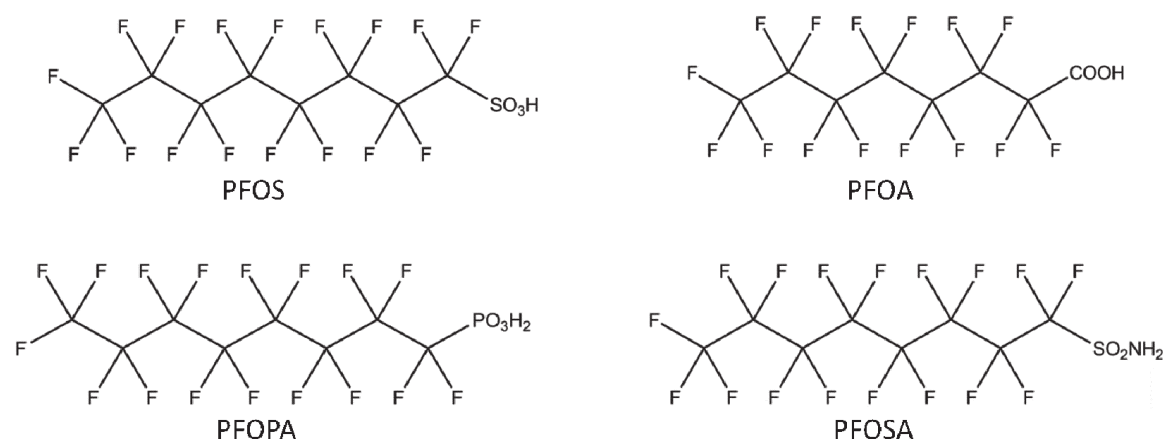

1. irudia. Buru hidrofiliko desberdina duten zenbait PFAS: PFOS-a (azido perfluooktanosulfonikoa), PFOA (azido perfluoroooktanoikoa), PFOPA (azido perfluorooktanofosfonikoa) eta PFOSA (perfluorooktanosulfonamida). 
Fluordun konposatuak gure kostaldeko bizidunetan

Egun, PFAS-ek kezka larria sortu dute gizartean erakutsi duten toxikologia dela-eta; izan ere, kantzerigenoak edota disruptore endokrinoak direla frogatu da [5-7]. Kezka horri ingurumenean duten iraunkortasuna gehitu behar zaio, karbono-fluor lotura kimika organikoan aurkitutako lotura sendoenetarikoa baita. Hori dela-eta, hidrolisiarekiko, fotolisiarekiko, metabolismoarekiko edota biodegradazioarekiko erresistentzia handia erakusten dute [8]. Egonkortasun horrek eta duten erreaktibotasun baxuak biometatzeko gaitasuna ematen die.

Egun, konposatu horiek bizidunengan eragin dezaketen kaltea ezaguna den arren, oraindik ez dago konposatu horien erabilera debekatzen duen legedi finkorik. 2000. urtean PFAS-ak ekoizten dituen konpainia nagusiak (3M Konpainiak) kate luzeko PFAS-ak $(\mathrm{C}>8)$ kate laburreko $\left(\mathrm{C}_{4}-\mathrm{C}_{7}\right)$ PFAS-ek ordezkatuko zituztela iragarri zuen, azken horiek toxikotasun baxuagoa dutela uste baita [9]. 2006. urtean Kanadako eta Ameriketako Estatu Batuetako hainbat PFAS ekoizlek azido perfluorooktanoikoaren (perfluorooctanoic acid, PFOA, delakoaren), kate luzeko PFAS-en eta euren aitzindarien produkzioa murrizten joateko konpromisoa hartu zuten [10,11]. Urte horretatik aurrera, azido perfluorooktanosulfonikoaren (perfluorooctane sulfonic acid, PFOS, delakoaren) gainean jarri ziren begirada guztiak, eta azken hori da legedietan, mementoz, gehitu den PFAS bakarra. Besteak beste, 2009. urtean Stockholmoko hitzarmenaren arabera, PFOS kutsatzaile organiko iraunkor (persistent organic pollutant, POP, delako) moduan sailkatu eta bere erabilera mugatu zen [12]. Era berean, 2013. urtean 2013/39/ EU uraren esparru-direktibaren barruan gehitu zen lehentasunezko substantzia bezala eta ingurumenaren kalitate estandar (environmental quality standard, EQS, delako) balioa finkatu zen konposatu horrentzat bio$\tan (9,1 \mu \mathrm{g} / \mathrm{kg})[13]$. PFOS eta PFOA dira ingurumeneko lan gehienetan monitorizatutako konposatuak.

Murrizketa horiek guztiek fluordun konposatu berrien erabilera ekarri dute, hala nola, polifluoroalkil fosfatuena (polyfluoroalkyl phosphates, PAP, delakoena). Hala ere, konposatu berri horien arriskuaren beldurrez, azken urteotan, ohiko PFAS-ez gain, fluordun konposatu berriak ere aztertzen hasi dira [14]. Azken ikerketek konposatu horietako asko PFOA eta antzeko PFAS-en aitzindari direla frogatu dute; hala nola, PAP-ak, eta beraz, euren erabilera PFAS-en iturri berria bilakatu da $[15,16]$.

PFAS-en presentzia ingurumenean oso nabaria izaten ari da azken urteotan. Konposatu horien agerpena iturri antropologikoei egozten zaie batez ere. Hala ere, euren agerpena ez da iturri horietatik gertu bakarrik antzeman; izan ere, euren presentzia puntu horietatik urrun ere aurkitu baita, esate baterako Artikoan [17] eta antartikoan [18]. Konposatu horien garraioa bi bide nagusitatik egitea espero da [19]. Alde batetik, PFAS-en aitzindariak diren hainbat konposatu neutro eta lurrunkor garraio atmosfe- 
Itsaso Zabaleta, Dennis Bilbao, Ekhine Bizkarguenaga, Ailette Prieto, Olatz Zuloaga

rikoari esker barreiatzea espero da, ondoren, aitzindari horiek dagozkien PFAS-etara degradatzeko. Bestalde, ionikoak diren PFAS-ak ur-sistemetan zehar hedatuz doaz eta beraien presentzia urrutiko lurraldetara hedatzen da. Azken urteotan giza odoletan [20-23] zein giza esnetan [24-26] aurkitutako PFAS mailak ikusita, kezka larria sortu da. Konposatu horiek gizakietara heltzeko dituzten bideetatik edateko ura [27,28], biota $[29,30]$, janarien ontziratze-materialak $[31,32]$ eta airea edo hautsa $[33,34]$ dira aipagarrienak.

Organismo itsastarrak bizi diren ur-sistemako kutsaduraren oso bioadierazle egokiak dira, bertan biometatzen baitira uretan dauden kutsatzaileak. Horretaz gain, organismo horiek gizaki edota kate trofikoan gorago dagoen beste bizidunen jaki direnez gero, gure gorputzean zenbateko kutsatzaile-maila sartzeko arriskua dagoen jakiteko erabil daitezke. Ostrak, muskuiluekin batera, sarri erabiltzen dira ohiko kutsatzaileen monitorizazioa gauzatzeko ur-sistemetan [35]. Bestalde, PFAS-en kasuan, kate trofikoan gora kutsatzaile horien kontzentrazio altuagoak aurkitzen direla ikusi da zenbait ikerketa-lanetan [36]. PFAS-en ezaugarriak direla-eta (hidrofobikoak izateaz gain lipofobikoak ere badirenez gero), gantz asko duten ehunetan metatu beharrean, proteinetan aberatsak diren ehunetan metatzeko joera dute, hala nola, odolean, gibelean edo giltzurrunean. Ildo horri jarraituz, ondoko lanean Frantziako, Euskal Herriko, Espainiako eta Portugaleko kostaldeetan arrantzatutako lazun (Chelon labrosus) eta ostrak (Ostrea edulis) aztertu dira, gure ingurumenaren kutsaduraren balorazio bat egin ahal izateko.

\section{LAZUNEN GIBELA ETA OSTRAK}

Lan honetan Frantziako, Euskal Herriko, Espainiako eta Portugaleko kostaldeetan arrantzatutako lazun eta ostretan 14 PFAS-en eta 10 aitzindariren monitorizazioa burutu da (ikusi 1. taula).

\subsection{Lagin-biltzea}

20-22 cm-ko tamainako lazunak Euskal kostaldeko puntu desberdinetan arrantzatu dira (ikus 2. irudia): Gernikan (Urdaibaiko itsasadarrean, araztegiko irteeratik gertu, Urdaibaiko Biosfera Erreserba) 2007, 2009, 2010, 2012 eta 2014ko udaberrian zehar, Plentziako portuan 2009ko udazken eta 2010eko udan zehar, Arriluzeko portuan 2007ko udazkenean eta udaberrian, eta 2010eko udaberrian zehar, eta Pasaiako portuan 2009ko udazkenean, 2010eko udan eta 2012ko udaberrian zehar. Lazunak arrantza tradizionala erabiliz arrantzatu eta Euskal Herriko Unibertsitateko (UPV/ EHU) Bioetika batzordearen arauen arabera disekzionatu dira. Behin disekzioa eginda, gibela $-80{ }^{\circ} \mathrm{C}$-an gorde da analisia egin arte. 
Fluordun konposatuak gure kostaldeko bizidunetan

1. taula. Monitorizatutako PFAS-en izena, ikurra, formula kimikoa eta metodoaren detekzio-mugak.

\begin{tabular}{|c|c|c|c|c|}
\hline \multirow[t]{2}{*}{ Ikurra } & \multirow[t]{2}{*}{ Analitoa } & \multirow[t]{2}{*}{ Formula } & \multicolumn{2}{|c|}{$\begin{array}{c}\text { Metodoaren } \\
\text { detekzio-muga } \\
(\mathrm{ng} / \mathrm{g})^{*}\end{array}$} \\
\hline & & & Gibela & Ostra \\
\hline PFBA & Azido perfluorobutanoikoa & $\mathrm{CF}_{3}\left(\mathrm{CF}_{2}\right)_{2} \mathrm{COOH}$ & 0,5 & 0,7 \\
\hline PFPeA & Azido perfluoropentanoikoa & $\mathrm{CF}_{3}\left(\mathrm{CF}_{2}\right)_{3} \mathrm{COOH}$ & 1,1 & 0,7 \\
\hline PFHxA & Azido perfluorohexanoikoa & $\mathrm{CF}_{3}\left(\mathrm{CF}_{2}\right)_{4} \mathrm{COOH}$ & 0,8 & 0,6 \\
\hline PFHpA & Azido perfluoroheptanoikoa & $\mathrm{CF}_{3}\left(\mathrm{CF}_{2}\right)_{5} \mathrm{COOH}$ & 0,2 & 0,2 \\
\hline PFOA & Azido perfluorooktanoikoa & $\mathrm{CF}_{3}\left(\mathrm{CF}_{2}\right)_{6} \mathrm{COOH}$ & 0,1 & 0,1 \\
\hline PFNA & Azido pefluorononanoikoa & $\mathrm{CF}_{3}\left(\mathrm{CF}_{2}\right)_{7} \mathrm{COOH}$ & 0,2 & 0,1 \\
\hline PFDA & Azido perfluorodekanoikoa & $\mathrm{CF}_{3}\left(\mathrm{CF}_{2}\right)_{8} \mathrm{COOH}$ & 0,2 & 0,1 \\
\hline PFBS & Azido perfluorobutanosulfonikoa & $\mathrm{CF}_{3}\left(\mathrm{CF}_{2}\right)_{3} \mathrm{SO}_{3} \mathrm{H}$ & 1,2 & 0,8 \\
\hline PFHxS & Azido perfluorohexanosulfonikoa & $\mathrm{CF}_{3}\left(\mathrm{CF}_{2}\right)_{5} \mathrm{SO}_{3} \mathrm{H}$ & 1,1 & 1,3 \\
\hline PFOS & Azido perfluorooktanosulfonikoa & $\mathrm{CF}_{3}\left(\mathrm{CF}_{2}\right)_{7} \mathrm{SO}_{3} \mathrm{H}$ & 0,3 & 0,2 \\
\hline PFHxPA & Azido perflurohexanofosfonikoa & $\mathrm{CF}_{3}\left(\mathrm{CF}_{2}\right)_{5} \mathrm{PO}_{3} \mathrm{H}_{2}$ & 0,9 & 0.6 \\
\hline PFOPA & Azido perfluorooktanofosfonikoa & $\mathrm{CF}_{3}\left(\mathrm{CF}_{2}\right)_{7} \mathrm{PO}_{3} \mathrm{H}_{2}$ & 2,2 & 2,4 \\
\hline PFDPA & Azido perfluorodekanofosfonikoa & $\mathrm{CF}_{3}\left(\mathrm{CF}_{2}\right)_{9} \mathrm{PO}_{3} \mathrm{H}_{2}$ & 1,9 & 2,4 \\
\hline FOSA & Perfluorooktanosulfonamida & $\mathrm{CF}_{3}\left(\mathrm{CF}_{2}\right)_{7} \mathrm{SO}_{2} \mathrm{NH}_{2}$ & 1,3 & 3,8 \\
\hline $6: 2$ monoPAP & $1 \mathrm{H}, 1 \mathrm{H}, 2 \mathrm{H}, 2 \mathrm{H}$-perfluorooktil fosfatoa & $\mathrm{CF}_{3}\left(\mathrm{CF}_{2}\right)_{5} \mathrm{CH}_{2} \mathrm{CH}_{2} \mathrm{O}-\mathrm{P}(\mathrm{O})(\mathrm{OH})_{2}$ & 2,7 & 0,5 \\
\hline 8:2 monoPAP & $1 \mathrm{H}, 1 \mathrm{H}, 2 \mathrm{H}, 2 \mathrm{H}$-perfluorodezil fosfatoa & $\mathrm{CF}_{3}\left(\mathrm{CF}_{2}\right)_{7} \mathrm{CH}_{2} \mathrm{CH}_{2} \mathrm{O}-\mathrm{P}(\mathrm{O})(\mathrm{OH})_{2}$ & 1,0 & 1,7 \\
\hline $6: 2$ diPAP & Bis $(1 \mathrm{H}, 1 \mathrm{H}, 2 \mathrm{H}, 2 \mathrm{H}$-perfluorooktil) fosfatoa & $\left(\mathrm{CF}_{3}\left(\mathrm{CF}_{2}\right)_{5} \mathrm{CH}_{2} \mathrm{CH}_{2} \mathrm{O}\right)_{2}-\mathrm{P}(\mathrm{O}) \mathrm{OH}$ & 1,9 & 0,6 \\
\hline 8:2 diPAP & Bis $(1 \mathrm{H}, 1 \mathrm{H}, 2 \mathrm{H}, 2 \mathrm{H}$-perfluorodezil) fosfatoa & $\left(\mathrm{CF}_{3}\left(\mathrm{CF}_{2}\right)_{7} \mathrm{CH}_{2} \mathrm{CH}_{2} \mathrm{O}\right)_{2}-\mathrm{P}(\mathrm{O}) \mathrm{OH}$ & 4,1 & 0,5 \\
\hline 6:2 FTCA & Azido 2-perfluorohexil etanoikoa & $\mathrm{CF}_{3}\left(\mathrm{CF}_{2}\right)_{5} \mathrm{CH}_{2} \mathrm{COOH}$ & 0,5 & 1,3 \\
\hline 8:2 FTCA & Azido 2-perfluorooktil etanoikoa & $\mathrm{CF}_{3}\left(\mathrm{CF}_{2}\right)_{7} \mathrm{CH}_{2} \mathrm{COOH}$ & 1,2 & 0,7 \\
\hline 6:2 FTUCA & Azido 2H-perfluoro-2-oktenoikoa & $\mathrm{CF}_{3}\left(\mathrm{CF}_{2}\right)_{4} \mathrm{CF}=\mathrm{CHCOOH}$ & 0,9 & 0,3 \\
\hline $8: 2$ FTUCA & Azido 2H-perfluoro-2-dezenoikoa & $\mathrm{CF}_{3}\left(\mathrm{CF}_{2}\right)_{6} \mathrm{CF}=\mathrm{CHCOOH}$ & 1,6 & 0,4 \\
\hline 5:3 FTCA & Azido 3-perfluoropentil propanoikoa & $\mathrm{CF}_{3}\left(\mathrm{CF}_{2}\right)_{4} \mathrm{CH}_{2} \mathrm{CH}_{2} \mathrm{COOH}$ & 0,3 & 0,4 \\
\hline 7:3 FTCA & Azido 3-perfluoroheptil propanoikoa & $\mathrm{CF}_{3}\left(\mathrm{CF}_{2}\right)_{6} \mathrm{CH}_{2} \mathrm{CH}_{2} \mathrm{COOH}$ & 0,9 & 0,3 \\
\hline
\end{tabular}

* Metodoaren detekzio-mugak Zabaleta eta lankideen lanean optimizatuta [37].

Bestalde, bai kultibatutako, bai basatiak diren ostrak ere bildu dira 2013. urteko apiril-maiatzean Frantziako kostaldean (La Rochelle eta Arcachon), Euskal kostaldean (Urdaibai), Espainiar kostaldean (Ostranor) eta Portugaleko kostaldean (Aveiro eta Sado). 
Itsaso Zabaleta, Dennis Bilbao, Ekhine Bizkarguenaga, Ailette Prieto, Olatz Zuloaga

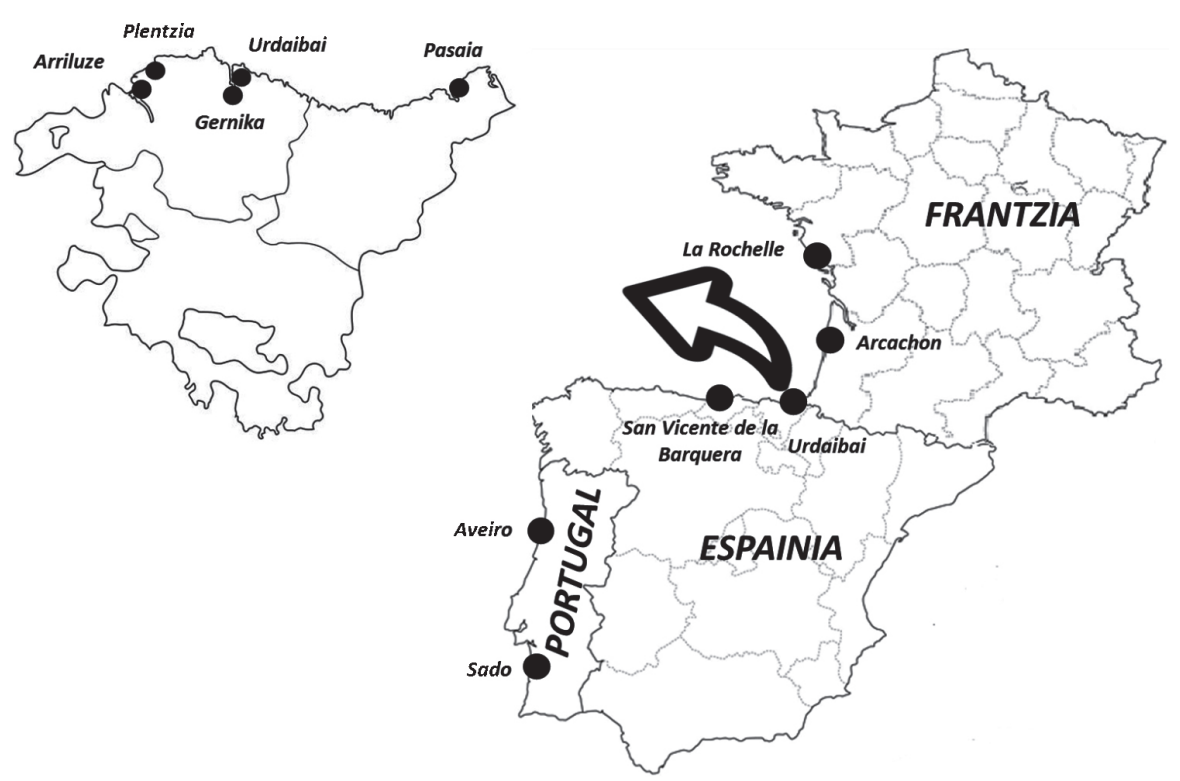

2. irudia. Lazun eta ostren laginak biltzeko puntuak.

\subsection{Laginen erauzketa eta analisia}

Gibel- eta ostra-laginetatik PFAS-ak erauzteko, aurretiaz gure lantaldean PFAS-ak arrainen gibelean, muskuluan edota muskuiluetan determinatzeko optimizatutako metodo analitikoa erabili da [37]. Metodo hori ultrasoinu fokatuaren bidezko solido-likido erauzketan (focused ultrasonic solid liquid extraction, FUSLE, delakoa) eta fase solidoaren erauzketaren bidezko garbiketan (solid phase extraction, SPE, delakoa) oinarritzen da (ikus 3. irudia). Laburki azalduta, laginaren $0,5 \mathrm{~g}$ pisatu eta $7 \mathrm{~mL}$ azetonitrilo:ur (9:1) nahastea erabilita erauzten da FUSLE erabiliz 2,5 minutuz. Lortutako erauzia $\mathrm{N}_{2}$ korrontea erabiliz $1 \mathrm{~mL}$-ra lurrundu eta SPE bidezko garbiketa-urratsa egiten da. Lehenik eta behin, kartutxoa $5 \mathrm{~mL}$ metanol eta $5 \mathrm{~mL}$ urekin egokitzen da eta lagina $6 \mathrm{~mL}$ urekin diluitu ondoren kargatzen da. Jarraian, garbiketa-urratsa egiten da $1 \mathrm{~mL} \% 2$ azido formiko eta $1 \mathrm{~mL}$ ur:metanol (95:5) nahastea erabiliz. Azkenik, PFASak $4 \mathrm{~mL}$ azetona (\% 2,5 amonio hidroxido) erabiliz eluitzen dira. Azken erauzia $\mathrm{N}_{2}$ korrontea erabiliz lurrunera eraman eta $250 \mu \mathrm{L}$ metanoletan berreratzen da. Behin laginak erauzita daudela, tandem masa-espektrometroari akoplatutako likido-kromatografoa (LC-MS/MS) erabili da analisia egiteko [37]. 


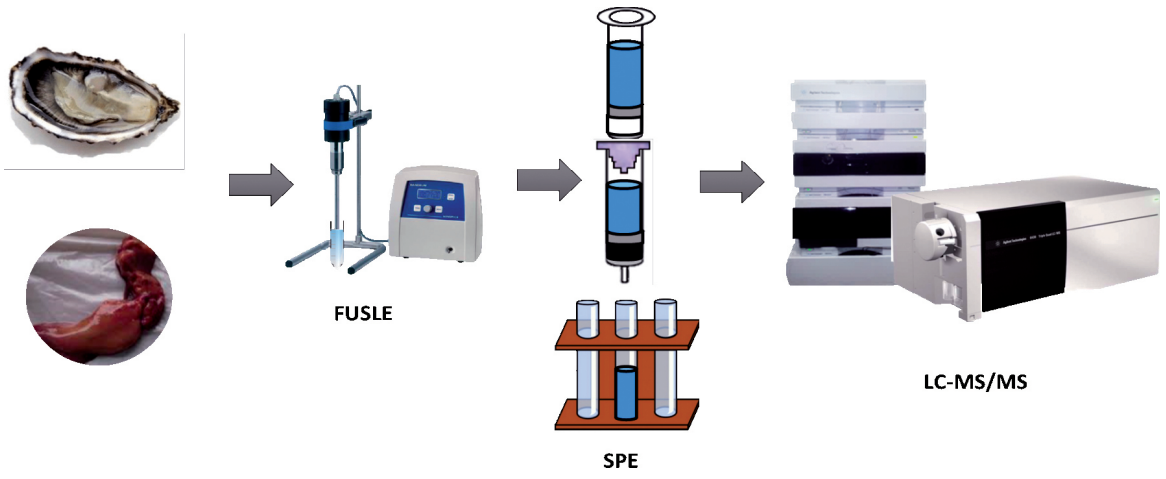

3. irudia. Gibela eta ostrak erauzteko eta analizatzeko prozedura esperimentalaren eskema.

\subsection{Lazun-gibeletan eta ostretan behatutako PFAS-ak eta euren kontzentrazioak}

\subsubsection{Lazunen gibela}

Bai laginak biltzeko puntu guztietan, bai aztertutako urte desberdinetan PFOS-a izan da detektatutako PFAS-a nagusia perfluorooktanosulfonamidak (perfluorooctane sulfonamide, PFOSA, delakoa) eta azido perfluorodekanoikoak (perfluorodecanoic acid, PFDA, delakoa) jarraituta, hurrenez hurren (ikusi 4. irudia). 2009. urtean Plentzian arrantzatutako lazun-gi-
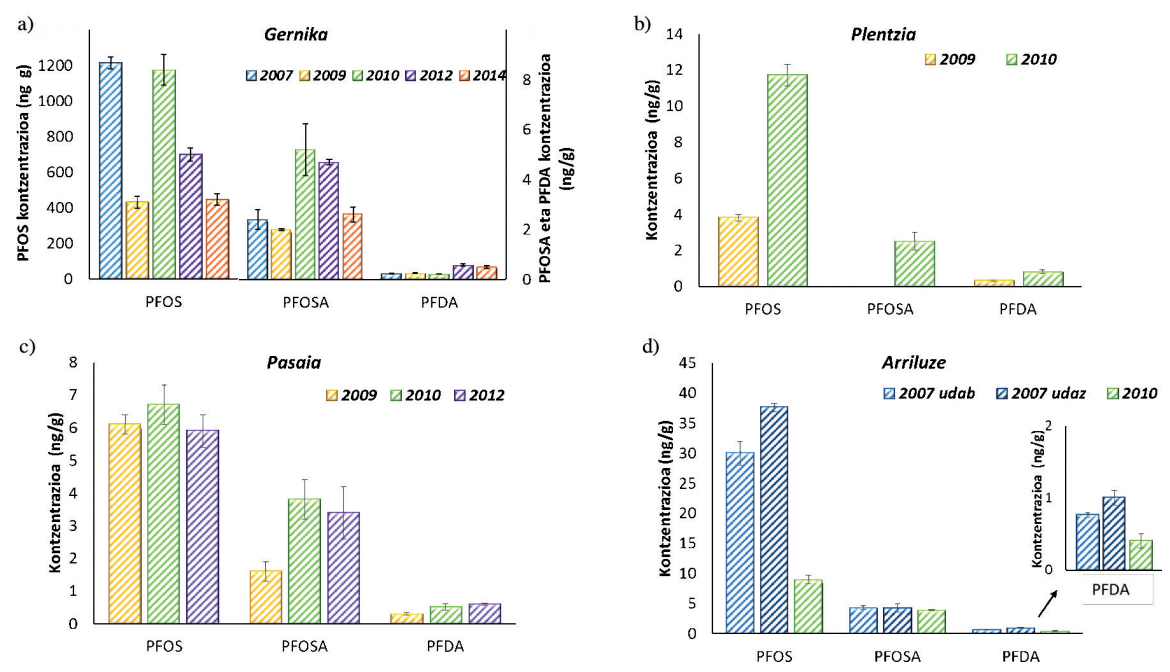

4. irudia. Lazunen gibeletan kuantifikatutako PFAS-en kontzentrazioa (ng/gtan) laginak biltzeko puntu desberdinetan: (a) Gernika, (b) Plentzia, (c) Pasaia eta (d) Arriluze. 
Itsaso Zabaleta, Dennis Bilbao, Ekhine Bizkarguenaga, Ailette Prieto, Olatz Zuloaga

bela da bakarra PFOSA detektatu arren, kontzentrazioa detekzio-mugetatik behera egon dena. Bestalde, ikertu diren aitzindarietatik, 8:2 diPAP-a detektatu da laginak biltzeko puntu guztietan eta 6:2 diPAP-a Gernikan eta Pasaian; hala ere, balioak beti metodoaren detekzio-muga azpitik egon dira.

Laginak biltzeko puntu desberdinetan detektatutako PFOSA $(1,6-4,7 \mathrm{ng} / \mathrm{g}$ Gernikan, < detekzio-muga - 2,5 ng/g Plentzian, 1,6-3,8 ng/g Pasaian eta 3,94,3 ng/g Arriluzen) eta PFDA (0,2-0,6 ng/g Gernikan, 0,3-0,8 ng/g Plentzian, 0,3-0,6 ng/g Pasaian eta 0,4-1,0 ng/g Arriluzen) kontzentrazioak nahiko parekoak izan arren, PFOS-aren kasuan desberdintasun nabaria dago laginak biltzeko puntuen artean. Urdaibaiko Biosfera Erreserban aurkitzen den laginak biltzeko puntuan (Gernikan) $1.214 \mathrm{ng} / \mathrm{g}$-rainoko kontzentrazioak aurkitu dira. Hala ere, ez da lehen aldia gure ikerketa-taldean egindako lanetan laginak biltzeko puntu horretan hainbat kutsatzaileren kontzentrazio altuak aurkitu direla. Aipatzekoak dira Gernikako lazunen (Chelon Labrosus) gibeletan beste zenbait konposatu disruptore endokrinotan behatutako alkilfenolen (629-679 ng/g tartean), Bisfenol-A-ren (BPA-ren, $97 \mathrm{ng} / \mathrm{g}$ ) eta ftalatoen (361 ng/g) kontzentrazio altuak [38]. Gernikako laginak biltzeko puntu horretan horren kontzentrazio altuak detektatzearen arrazoiak desberdinak izan daitezke; alde batetik, lazunak arrantzatu diren puntutik oso gertu araztegia aurkitzen da, zeinak uraren tratamendu primarioa egin ondoren, emaria berriro itsasadarrera isurtzen duen. Era berean, Gernikan hainbat industria dago, hala nola, metalurgia, automozioa, eta plastiko industria. Hori dela-eta, industria horien guztien hondakinak zenbait kutsatzaileren balio altuen adierazgarri izan daitezke. Azkenik, aipatzekoa da laginak biltzeko puntutik gertu suhiltzaileen parkea dagoela, non erabiltzen diren sua itzaltzeko aparrak PFOS-en iturri izan daitezkeen. Lan honetan lortutako PFOS kontzentrazio-maila kezkagarrien pareko edo altuagoak ere argitaratu dira beste zenbait herrialdetan; hala nola, Japonen Tropidinius amoenus generoko arrainen gibeletan 7.900 ng/g-rainoko PFOS kontzentrazioak detektatu dira. Lan horren egileek diotenez, arrainak arrantzatu ziren puntutik gertu armada base bat eta zentral elektriko bat daude. Uste dutenez, armada basean erabiltzen den sua itzaltzeko aparrak izan litezke PFOS kontzentrazio horien erantzule [39]. Belgikan, ordea, karpa (Cyprinus carpio) eta angira (Anguilla anguilla) gibeletan 1.822 eta $9.031 \mathrm{ng} / \mathrm{g}$-rainoko PFOS kontzentrazioak detektatu dira zonalde industrial batetik gertu [40]. Azkenik, Taiwanen Tilapia izeneko arrainetan $28.933 \mathrm{ng} / \mathrm{g}$-rainoko kontzentrazioak aurkitu dituzte industriako urak tratatzen dituen araztegitik hurbil dagoen ibai batean [41]. Adibide horiek guztiek argitara ateratzen dute PFOS-aren erabilerari dagokionez zenbait debeku jarri arren, gure organismo itsastarretan oraindik konposatu horren kontzentrazio-maila altuak daudela. Izan ere, PFOS-aren kasuan biotarako finkatuta dagoen EQS balioa $(9,1 \mathrm{ng} / \mathrm{g})$ erraz gainditu da. Azpimarragarriena Gernikan balio hori 100 aldiz gainditu izana bada 
Fluordun konposatuak gure kostaldeko bizidunetan

ere, Arriluzeko laginetan ere gainditu dela. Arriluzeko portua Getxoko kirol-portuaren parean egoteaz gain, Santurtziko merkataritza-portua du aurrez aurre. Horretaz gain, itsasadarra baino apur bat gorago zenbait suhiltzaile-parkez gain, Galindoko araztegia dago (Euskal Herriko handiena eta Espainiako handienetarikoa), zeinak uraren tratamendu sekundarioa egin ondoren, $289.000 \mathrm{~m}^{3} /$ egun-eko emaria isurtzen duen Galindo ibaira, zeinak itsasadarrarekin egiten duen bat metro gutxitara. Zaila da detektatutako PFAS-en iturri zehatza zein den aurresatea, bai araztegia, bai suhiltzaileen parkeak, baita portuetako jarduerak iturri argiak izan daitezkeelako. Horretaz gain, lazunak puntu finko batean egon beharrean mugimenduan daudenez gero, erakutsitako PFAS-a kontzentrazioen jatorriak denboran zehar desberdinak izan daitezke. Bestalde, Plentzia eta Pasaia izan dira PFAS-en kontzentraziorik baxuenak erakutsi dituzten puntuak. Plentziako portuan industria edota beste jarduerarik ez dagoen bitartean, Pasaiako portuan zenbait industria (paper-, metal- eta margo-industria) daude. Hala ere, industria horiek PFAS-en iturri nagusi ez direla esan daiteke.

Azkenik, urteen zeharreko joera argirik ez da ageri. Gernikan, 2009. urtean 2007. urtearekin konparatuta, PFOS-en beherakada ikusten den arren ( $p<0,05$, faktore bakarreko bariantza-analisia, analysis of variance, ANOVA, delakoa), 2010. urtean hasierako balioak detektatzen dira berriro $(p>0,05)$. 2010. urteaz geroztik, PFOS-en eta PFOSA-ren kontzentrazioan beherakada sumatu da $(p<0,05)$. Hala ere, gainontzeko puntuetan ikusten den joera ez da guztiz parekoa. Plentziaren kasuan, Gernikan ikusi bezala, 2010. urtean igoera bat ikusten den bitartean $(p<0,05)$, Arriluzen kontrako joera dagoela esan daiteke. Bestalde, Pasaian, urteak pasatu ahala, ez da aldaketa askorik ikusten $(p>0,05)$ (soilik PFOSA-ren kasuan ikusi da igoera). Azkenik, Arriluzen 2007. urtean, bi urtarotan arrantzatu eta gero (udaberria eta udazkena), emaitza nahiko parekoak direla esan daiteke PFOSA-rentzat eta PFDA-rentzat $(p>0,05)$, PFOS-entzat udazkenean igoera txiki bat ikusten den bitartean $(p<0,05)$. Konposatu horien joera denboran zehar ikusteko, monitorizazio-kanpaina gehiago beharko lirateke.

\subsubsection{Ostrak}

Lan honetan bildu diren ostrak Frantziako, Euskal Herriko, Espainiako eta Portugaleko kostaldeetan dute jatorria. Kasu honetan PFOS-a eta PFOSA izan dira detektatutako fluordun konposatu bakarrak (ikusi 2. taula). Frantziako kostaldeko eta Urdaibaiko ostretan bakarrik aurkitu dira aipatutako konposatuak. Munschy eta lankideek [42] 2010. urtean Frantziako hiru kostaldetan zehar (Mantxako kanala, kostalde mediterraneoa eta kostalde atlantikoa) bildu zituzten ostrak (C.gigas), Arcachon-en barne. Atlantiko kostaldean 0,03-0,1 ng/g tarteko PFOS kontzentrazioak, $0,57 \mathrm{ng} / \mathrm{g}$ PFOSA eta $0,08 \mathrm{ng} / \mathrm{g}$ PFDA detektatu dituzte. Lan honetan, Frantziar kostaldean detektatutako PFOS kontzentrazioak apur bat altua- 
Itsaso Zabaleta, Dennis Bilbao, Ekhine Bizkarguenaga, Ailette Prieto, Olatz Zuloaga

2. taula. Analizatutako ostren kontzentrazioak eta desbideratze estandarrak (ng/g-tan).

\begin{tabular}{l|lcc}
\hline Lagin-biltze puntua & \multicolumn{1}{|c}{ Lagina } & PFOS & PFOSA \\
\hline Arcachon & Ostra basatia & $0,54 \pm 0,06$ & $0,6 \pm 0,1$ \\
& Ostra kultibatua & $1,0 \pm 0,2$ & $<\mathrm{MDL}$ \\
\hline La Rochelle & Ostra basatia & $0,28 \pm 0,06$ & $0,68 \pm 0,01$ \\
& Ostra kultibatua & $1,72 \pm 0,03$ & $<\mathrm{MDL}$ \\
\hline Urdaibai & Ostra basatia & $1,0 \pm 0,2$ & $<\mathrm{MDL}$ \\
\hline Ostranor & Ostra kultibatua & $<\mathrm{MDL}$ & $<\mathrm{MDL}$ \\
\hline Aveiro & Ostra kultibatua & $<\mathrm{MDL}$ & $<\mathrm{MDL}$ \\
\hline Sado & Ostra basatia & $<\mathrm{MDL}$ & $<\mathrm{MDL}$ \\
\hline
\end{tabular}

<MDL: kontzentrazioa metodoaren detekzio-mugatik behera.

goak izan arren $(0,28-0,54 \mathrm{ng} / \mathrm{g})$, PFOSA kontzentrazio parekoak lortu dira (0,60-0,68 ng/g). Gure kasuan PFDA ez da detektatu.

Ostra kultibatu edo basatien arteko erkaketa eginez gero, Arcachon eta La Rochelle-n kasuan, ostra kultibatuek PFOS kontzentrazio altuagoa erakutsi dute bi kasuetan. Horren arrazoia ostrak kultibatzeko erabilitako itsasoko ura izan daiteke, izan ere, argitaratutako zenbait lanek PFOS-aren presentzia itsasoko uretan berresten baitute [43]. PFOSA, ordea, ostra basatietan bakarrik detektatu da. Hala ere, esan beharra dago kontzentrazioak ez direla altuak eta hipotesi argirik ezin dela proposatu.

Ostren kontzentrazio-mailak lazun-gibeletan aurkitutako kontzentrazio-mailak baino baxuagoak izan dira. Alde batetik, egia da lazun-gibelak eta ostrak ez direla laginak biltzeko puntu berdinetan bildu; beraz, kontzentrazio-mailen erkaketa zuzena egitea ez da posible. Hala ere, hainbat lanetan ondorioztatu den bezala, PFAS-ek proteinetara lotzeko duten gaitasuna kontuan izanda eta kate trofikoan gora egin ahala duten metatzeko ahalmen handiagoa kontuan izanda [36], arrain-gibeletan ostretan baino kontzentrazio-maila altuagoak aurkitzea espero da. Lortutako emaitzekin arrain-gibela ur-sistemen kutsadura-egoera zein den aurresateko bioadierazle egokia dela ondoriozta daiteke.

\section{ONDORIOAK}

Organismo itsastarrak gure ur-sistemen kutsaduraren adierazle ezin hobeak dira. Horri esker, lan honetan Frantziako, Euskal Herriko, Espainiako 
Fluordun konposatuak gure kostaldeko bizidunetan

eta Portugaleko zenbait puntutako kostaldeko kutsaduraren emaitzak plazaratu dira. Pasaia, Gernika, Plentzia eta Arriluzen arrantzatutako lazunen gibeletan PFOS-a, PFOSA eta PFDA detektatu dira. PFOS-a izan da laginak biltzeko puntu guztietan gailendu den konposatua, eta Gernikako puntuan detektatutako kontzentrazio-mailek zer pentsa handia eman beharko lukete. Bai araztegia, bai Gernika inguruko industria edo suhiltzaile-parkea izan daitezke horren iturri nagusiak. Ostren kasuan, gibelak baino PFAS-ak metatzeko gaitasun baxuagoa dutela ikusi da, PFAS-ek organismoen proteinetara lotzeko joera berrets daitekeelarik. Kasu honetan, PFOS-a eta PFOSA dira detektatutako PFAS-ak. Esan liteke konposatu horien azterketa ur-sistemetan egiteko arrainen gibela bioadierazle egokia dela.

\section{ESKER ONAK}

Lan hau Zientzia eta Berrikuntza Ministerioko CTM2014-56628-C31-R proiektu barruan garatu da. Itsaso Zabaletak eta Ekhine Bizkarguenagak eskerrak eman nahi dizkiote Euskal Herriko Unibertsitateari beren doktoretza aurreko eta ondoko diru-laguntzengatik, hurrenez hurren.

\section{BIBLIOGRAFIA}

[1] EDU LARTZANGUREN. 2016. «Mendiko arropa garbitzen». Berria Egunkaria. http://www.berria.eus/paperekoa/1835/038/001/2016-01-29/ mendiko_arropa_garbitzen.htm (2016ko urtarrilaren 29an).

[2] RICHARDSON S.D. 2012. «Environmental Mass Spectrometry: Emerging Contaminants and Current Issues». Anal Chem, 84, 747-778.

[3] JAHNKE A. eta BERGER U. 2009. «Trace analysis of per- and polyfluorinated alkyl substances in various matrices-How do current methods perform?». J Chromatogr A, 1216, 410-421.

[4] HERZKE D., OLSSON E. eta POSNER S. 2012. «Perfluoroalkyl and polyfluoroalkyl substances (PFASs) in consumer products in Norway - A pilot study». Chemosphere, $\mathbf{8 8}, 980-987$.

[5] LAU C., ANITOLE K., HODES C., LAI D., PFAHLES-HUTCHENS A. eta SEED J. 2007. «Perfluoroalkyl Acids: A Review of Monitoring and Toxicological Findings». Toxicol Sci, 99, 366-394.

[6] LAU C., BUTENHOFF J.L. eta ROGERS J.M. 2004. «The developmental toxicity of perfluoroalkyl acids and their derivatives». Toxicol Appl Pharmacol, 198, 231-241.

[7] ANDERSEN M.E., BUTENHOFF J.L., CHANG S-C., FARRAR D.G., KENNEDY G.L., LAU C., OLSEN G.W., SEED J. eta WALLACE K.B. 2008. «Perfluoroalkyl Acids and Related Chemistries-Toxicokinetics and Modes of Action». Toxicol Sci, 102, 3-14. 
Itsaso Zabaleta, Dennis Bilbao, Ekhine Bizkarguenaga, Ailette Prieto, Olatz Zuloaga

[8] NAILE J.E., KHIM J.S., WANG T., CHEN C., LUO W., KWON B-O., PARK J., KOH C-H., JONES P.D., LU Y. eta GIESY J.P. 2010. «Perfluorinated compounds in water, sediment, soil and biota from estuarine and coastal areas of Korea». Environ Pollut, 158, 1237-1244.

[9] 3M COMPANY. 2000. «Phase-out Plan for POSF-based products». U.S. EPA Adm. Rec., AR226-0600.

[10] ENVIRONMENT AND CLIMATE CHANGE IN CANADA. 2006 «Environment and climate change in Canada: Environmental Performance Agreement Respecting Perfluorocarboxylic Acids (PFCAs) and their Precursors in Perfluorinated Products Sold in Canada».

[11] US EPA. 2006. "US EPA: PFOA Stewardship Program. US EPA 2010/2015».

[12] STOCKHOLM CONVENTION. 2009. «Stockholm Convention, List of POPs in the Stockholm Convention». (http://chm.pops.int/Convention/ ThePOPs/ListingofPOPs/tabid/2509/Default.aspx).

[13] DIRECTIVE 2013/39/EU OF THE EUROPEAN PARLIAMENT AND OF THE COUNCIL OF 12 AUGUST 2013 AMENDING DIRECTIVES 2000/60/EC AND 2008/105/EC AS REGARDS PRIORITY SUBSTANCES IN THE FIELD OF WATER POLICY. 2013.

[14] WANG Z., COUSINS I.T., SCHERINGER M. eta HUNGERBÜHLER K. 2013. «Fluorinated alternatives to long-chain perfluoroalkyl carboxylic acids (PFCAs), perfluoroalkane sulfonic acids (PFSAs) and their potential precursors». Environ Int, 60, 242-248.

[15] LEE H., D'EON J. eta MABURY S.A. 2010. «Biodegradation of Polyfluoroalkyl Phosphates as a Source of Perfluorinated Acids to the Environment». Environ Sci Technol, 44, 3305-3310.

[16] D'EON J.C. eta MABURY S.A. 2011. «Exploring Indirect Sources of Human Exposure to Perfluoroalkyl Carboxylates (PFCAs): Evaluating Uptake, Elimination, and Biotransformation of Polyfluoroalkyl Phosphate Esters (PAPs) in the Rat». Environ Health Perspect, 119, 344-350.

[17] MARTIN J.W., SMITHWICK M.M., BRAUNE B.M., HOEKSTRA P.F., MUIR D.C.G. eta MABURY S.A. 2004. «Identification of Long-Chain Perfluorinated Acids in Biota from the Canadian Arctic». Environ Sci Technol, 38, 373-380.

[18] LLORCA M., FARRÉ M., TAVANO M.S., ALONSO B., KOREMBLIT G. eta BARCELÓ D. 2012. «Fate of a broad spectrum of perfluorinated compounds in soils and biota from Tierra del Fuego and Antarctica». Environ Pollut, 163, 158-166.

[19] BOSSI R., STRAND J., SORTKJÆR O. eta LARSEN M.M. 2008. «Perfluoroalkyl compounds in Danish wastewater treatment plants and aquatic environments». Environ Int, 34, 443-450.

[20] TOMS L-M.L., CALAFAT A.M., KATO K., THOMPSON J., HARDEN F., HOBSON P., SJÖDIN A. eta MUELLER J.F. 2009. «Polyfluoroalkyl Chem- 
Fluordun konposatuak gure kostaldeko bizidunetan

icals in Pooled Blood Serum from Infants, Children, and Adults in Australia». Environ Sci Technol, 43, 4194-4199.

[21] ERICSON I., GÓMEZ M., NADAL M., VAN BAVEL B., LINDSTRÖM G. eta DOMINGO J.L. 2007. «Perfluorinated chemicals in blood of residents in Catalonia (Spain) in relation to age and gender: A pilot study». Environ Int, 33, 616-623.

[22] GLYNN A., BERGER U., BIGNERT A., ULLAH S., AUNE M., LIGNELL S. eta DARNERUD P.O. 2012. «Perfluorinated Alkyl Acids in Blood Serum from Primiparous Women in Sweden: Serial Sampling during Pregnancy and Nursing, And Temporal Trends 1996-2010». Environ Sci Technol, 46, 9071-9079.

[23] PAN Y., SHI Y., WANG J., CAI Y. eta WU Y. 2010. «Concentrations of perfluorinated compounds in human blood from twelve cities in China». Environ Toxicol Chem, 29, 2695-2701.

[24] FUJII Y., YAN J., HARADA K.H., HITOMI T., YANG H., WANG P. eta KOIZUMI A. 2012. «Levels and profiles of long-chain perfluorinated carboxylic acids in human breast milk and infant formulas in East Asia». Chemosphere, 86, 315-321.

[25] KADAR H., VEYRAND B., BARBAROSSA A., PAGLIUCA G., LEGRAND A., BOSHER C., BOQUIEN C-Y., DURAND S., MONTEAU F., ANTIGNAC J-P. eta LE BIZEC B. 2011. «Development of an analytical strategy based on liquid chromatography-high resolution mass spectrometry for measuring perfluorinated compounds in human breast milk: Application to the generation of preliminary data regarding perinatal exposure in France». Chemosphere, 85, 473-480.

[26] LLORCA M., FARRÉ M., PICÓ Y., TEIJÓN M.L., ÁLVAREZ J.G. eta BARCELÓ D. 2010. «Infant exposure of perfluorinated compounds: Levels in breast milk and commercial baby food». Environ Int, 36, 584-592.

[27] DING H., PENG H., YANG M. eta HU J. 2012. «Simultaneous determination of mono- and disubstituted polyfluoroalkyl phosphates in drinking water by liquid chromatography-electrospray tandem mass spectrometry». J Chromatogr A, 1227, 245-252.

[28] ULLAH S., ALSBERG T. eta BERGER U. 2011. «Simultaneous determination of perfluoroalkyl phosphonates, carboxylates, and sulfonates in drinking water». J Chromatogr A, 1218, 6388-6395.

[29] KANNAN K., CORSOLINI S., FALANDYSZ J., OEHME G., FOCARDI S. eta GIESY J.P. 2002. «Perfluorooctanesulfonate and Related Fluorinated Hydrocarbons in Marine Mammals, Fishes, and Birds from Coasts of the Baltic and the Mediterranean Seas». Environ Sci Technol, 36, 3210-3216.

[30] GIESY J.P. eta KANNAN K. 2001. «Global Distribution of Perfluorooctane Sulfonate in Wildlife». Environ Sci Technol, 35, 1339-1342.

[31] ZABALETA I., NEGREIRA N., BIZKARGUENAGA E., PRIETO A., COVACI A. eta ZULOAGA O. 2017. «Screening and identification of per- and 
Itsaso Zabaleta, Dennis Bilbao, Ekhine Bizkarguenaga, Ailette Prieto, Olatz Zuloaga

polyfluoroalkyl substances in microwave popcorn bags». Food Chem, 230, 497-506.

[32] ZAFEIRAKI E., COSTOPOULOU D., VASSILIADOU I., BAKEAS E. eta LEONDIADIS L. 2014. «Determination of perfluorinated compounds (PFCs) in various foodstuff packaging materials used in the Greek market». Chemosphere, 94, 169-176.

[33] SHOEIB T., HASSAN Y., RAUERT C. eta HARNER T. 2016. «Poly- and perfluoroalkyl substances (PFASs) in indoor dust and food packaging materials in Egypt: Trends in developed and developing countries». Chemosphere, 144, 1573-1581.

[34] ERICSON JOGSTEN I., NADAL M., VAN BAVEL B., LINDSTRÖM G. eta DOMINGO J.L. 2012. «Per- and polyfluorinated compounds (PFCs) in house dust and indoor air in Catalonia, Spain: Implications for human exposure». Environ Int, 39, 172-180.

[35] SARKAR A., RAY D., SHRIVASTAVA A.N. eta SARKER S. 2006. «Molecular Biomarkers: Their significance and application in marine pollution monitoring». Ecotoxicology, 15, 333-340.

[36] KELLY B.C., IKONOMOU M.G., BLAIR J.D., SURRIDGE B., HOOVER D., GRACE R. eta GOBAS F.A.P.C. 2009. «Perfluoroalkyl Contaminants in an Arctic Marine Food Web: Trophic Magnification and Wildlife Exposure». Environ Sci Technol, 43, 4037-4043.

[37] ZABALETA I., BIZKARGUENAGA E., PRIETO A., ORTIZ-ZARRAGOITIA M., FERNÁNDEZ L.A. eta ZULOAGA O. 2015. «Simultaneous determination of perfluorinated compounds and their potential precursors in mussel tissue and fish muscle tissue and liver samples by liquid chromatography-electrospray-tandem mass spectrometry». J Chromatogr A, 1387, 13-23.

[38] ROS O., VALLEJO A., OLIVARES M., ETXEBARRIA N. eta PRIETO A. 2016. «Determination of endocrine disrupting compounds in fish liver, brain, and muscle using focused ultrasound solid-liquid extraction and dispersive solid phase extraction as clean-up strategy». Anal Bioanal Chem, 408, 56895700 .

[39] TANIYASU S., KANNAN K., HORII Y., HANARI N. eta YAMASHITA N. 2003. «A Survey of Perfluorooctane Sulfonate and Related Perfluorinated Organic Compounds in Water, Fish, Birds, and Humans from Japan». Environ Sci Technol, 37, 2634-2639.

[40] HOFF P.T., VAN CAMPENHOUT K., VAN DE VIJVER K., COVACI A., BERVOETS L., MOENS L., HUYSKENS G., GOEMANS G., BELPAIRE C., BLUST R. eta DE COEN W. 2005. «Perfluorooctane sulfonic acid and organohalogen pollutants in liver of three freshwater fish species in Flanders (Belgium): relationships with biochemical and organismal effects». Environ Pollut, 137, 324-333.

[41] LIN A.Y-C., PANCHANGAM S.C., TSAI Y-T. eta YU T-H. 2014. «Occurrence of perfluorinated compounds in the aquatic environment as found in 
science park effluent, river water, rainwater, sediments, and biotissues». Environ Monit Assess, 186, 3265-3275.

[42] MUNSCHY C., MARCHAND P., VENISSEAU A., VEYRAND B. eta ZENDONG Z. 2013. «Levels and trends of the emerging contaminants HBCDs (hexabromocyclododecanes) and PFCs (perfluorinated compounds) in marine shellfish along French coasts». Chemosphere, 91, 233-240.

[43] GÓMEZ C., VICENTE J., ECHAVARRI-ERASUN B., PORTE C. eta LACORTE S. 2011. «Occurrence of perfluorinated compounds in water, sediment and mussels from the Cantabrian Sea (North Spain)». Mar Pollut Bull, 62, 948-955. 